\title{
The Role of the Family in the Adoption of a Vegan Diet. The Implications for Consumer Socialization towards Sustainable Food Consumption
}

\author{
Agnieszka Chwialkowska \\ University of West Georgia
}

Even though food consumption has a significant influence on our environment, diet remains an underappreciated component in global sustainability debates. This study investigates the long-term effects of socialization towards a vegan diet, which has the lowest environmental footprint. Family motives and values underlying the adoption of a vegan diet are studied. The long-term impact of this socialization on young adults is explored to identify the factors that affect the internalization of sustainable food consumption values into adulthood. This research contributes to the ongoing discussion by providing a theoretical foundation for understanding family differences in socialization towards sustainable food consumption. As longitudinal approach to studying sustainable food consumption has been largely overlooked by previous research, this study goes beyond prevalent child development stages and builds on the self-determination theory to investigate the long-term impact of socialization on the older children who no longer live with their families.

\section{INTRODUCTION}

Processes related to food production have a massive impact on the environment (Reisch \& Gwozdz, 2011). The production and preparation of various foods require different quantities of resources and varies in terms of greenhouse gas emissions, land requirements, and energy use. Thus, what we consume is strongly linked to our overall burden on the planet (Geeraert, 2013, p. 127). Also, a reduction in the negative environmental impact of agriculture (FAO, 2006) can only be achieved through dietary changes (UNEP, 2010). Therefore, our diet is a major factor in global sustainable development.

Previous research in the area of sustainability focuses on marketing green products, the effectiveness of different marketing strategies, and ethical aspects of green marketing (e.g. Kumar, 2016; Leonidou, et. al., 2011; Peattie, 2011; Richey, et. al., 2014; Rolland \& Bazzoni, 2009; Wang, et al., 2014). Another research stream focuses on identifying factors that drive or inhibit environmentally friendly behaviors and explores consumer motivations, intentions, attitudes, and effects of environmental concern on green purchases (De Groot \& Steg, 2007; Lin \& Huang, 2012; Luchs, Naylor, Irwin, \& Raghunathan, 2010; Griskevicius, Tybur, \& Van den Bergh, 2010). Even though food consumption has a significant influence on our environment (FAO, 2006; Geeraert, 2013; UNEP, 2010), diet remains an underdeveloped component in current global sustainability debates (Geeraert, 2013), thus a sustainable diet should be given more research attention.

The research stream studying drivers and barriers to sustainable behaviors explores environmentally friendly behaviors in the context of individual decisions (e.g., Lin \& Huang, 2012), but not in the context 
of socializing towards sustainable food consumption. We know that social norms can be either a key driver or impediment to green consumption (Bennett \& Williams, 2011; Brough 2016; Goldstein, Cialdini, \& Griskevicius, 2008). We first acquire certain norms and internalize beliefs and values within a family (Moore, Wilkie, \& Desrochers, 2017; Moschis, Gilbert, \& Churchil, 1978; Ward, 1974). This intergenerational influence is manifested in the acquisition of consumption patterns and other marketplace behaviors (Moore \& Moschis, 1981; Moschis, 1985). Intergenerational influence has also been shown to shape diet and influence products purchased in adulthood (Connel, Brucks, \& Nielsen, 2014; Moore, Wilkie \& Desrochers, 2017; Moore, Wilkie \& Lutz, 2002; Richins \& Chaplin, 2015). Therefore, behaviors learned in childhood often have a long-lasting effect. Childhood experiences shape our dietary preferences, how food tastes to us, and the emotions associated with different products and brands (Connel, Brucks, \& Nielsen, 2014; Moore, Wilkie \& Desrochers, 2017; Moore, Wilkie, \& Lutz, 2002; Richins \& Chaplin, 2015). However, despite it being a major socialization agent (Moschis, 1985), family and its role in sustainable food consumption, for the most part, has been ignored by marketing and social scientists and consumer researchers alike. Thus, there is a need for a better understanding of the nature of family influence, as well as the communication process involved in transmission and acquisition of proenvironmental values and behaviors from parents.

Another aspect that requires our attention relates to the longitudinal effects of socializing towards sustainable food consumption. As intergenerational influences on a diet are expected to weaken when young adults move away from the family home (Moore, Wilkie, \& Desrochers, 2017), understanding the determinants of long-term sustainable consumption is of paramount importance for society, families, and policymakers. Previous research looks at how consumer socialization impacts are internalized and persist into adulthood with regard to diet and health (e.g., Cottee \& Wood, 2004; Moore, et al., 2002), but not with respect to sustainable consumption. Therefore, researchers including John (1999), Moore, Wilkie and Desrochers (2017), and Wang, et al. (2011) call for investigating which elements of a diet are strongly integrated and remain into adulthood. Another important question is why they do, or do not.

In summary, what has been lacking in prior consumer behavior research is a theoretical basis for understanding distinctive values underlying family socialization towards sustainable food consumption and how they influence the internalization of sustainable food consumption motives into adulthood. Our research addresses these research gaps in several ways. As food consumption is a major contributor to our environmental burden on the planet, this research focuses on a sustainable diet and motivations to 'eat green'. As there is a need for better understanding of how the family is involved in transmission and acquisition of pro-environmental values and behaviors, this research investigates the socialization of children into this particular consumption pattern. Our focus on the family provides an insight into the immediate social environment and reveals how this environment shapes sustainable dietary values. The conceptual framework in this study is consistent with previous studies treating consumer socialization as an integral part of general socialization (Carlson \& Grossbart, 1988), and thus, consumer learning is considered a social process. To answer the calls for longitudinal studies in this area and to address a lack of understanding under what circumstances sustainable dietary values persist into adulthood, this study goes beyond prevalent child development stages. Even though the success of long-term socialization towards sustainable food consumption lies in the internalization of sustainability values, little attention has yet been paid to this topic. Thus we build on the self-determination theory to investigate the long-term impact of this socialization on the young adults who no longer live with their families and compare the impact of different family socialization types on how long-lasting the effects of these types of socialization are.

To do so, we conducted 71 interviews, analyzed grocery receipts and food consumption diaries of 21 families. Based on this data, this article details four types of inductively derived families based on their key motivations to eat a sustainable diet. Moreover, we identified the factors in family socialization that affect internalization of sustainable food consumption. Therefore, we looked at how different family consumption values, which underline the sustainable diet, shape long-term food preferences and eating habits of young adults. 


\section{LITERATURE REVIEW}

\section{Sustainable Food Consumption}

When considering conditions for sustainable food consumption, several factors should be taken into account: (1) Greenhouse gas emissions (an outcome of the use of fossil fuels and agricultural production processes) during production, transportation, storage, and consumption (including refrigeration, freezing, cooking), and waste disposal; (2) Land requirements for the production in $\mathrm{m}^{2}$ per $0.1 \mathrm{~kg}$; and (3) Energy use (Geeraert, 2013). Reduction of the negative environmental impact of agriculture (FAO, 2006) can only be achieved through dietary changes, including abstaining from or reducing the amount of animal products consumed (UNEP, 2010). Based on these criteria, a vegan plant-based diet that includes mostly locally grown foods and no animal products is considered the most sustainable.

In previous research, motives to 'buy green' were classified in terms of being intrinsic or extrinsic and capture several categories of social motives: concern for the environment, functional motives, health motives (Kim \& Choi, 2005; Lin \& Huang, 2012; Tanner \& Kast, 2003). However, despite their value in predicting future behavior, these motives have been mostly explored in the context of individual decisions to buy green products, but not in the context of socializing into specific consumption patterns or the longitudinal effects of this socialization.

\section{Consumer Socialization}

Social learning theory emphasizes the environmental sources of normative influence and learning. Through the socialization process, communication with others facilitates the diffusion of behavioral norms (De Gregorio \& Sung, 2010; Moschis \& Moore, 1984;). Socialization can be defined as an "adultinitiated process by which developing children, through insight, training, and imitation, acquire habits and values congruent with adaptation to their culture" (Baumrind, 1980, p. 640), and thus develop consumerrelated skills, knowledge, and attitudes (Maccoby, 2007; Moschis \& Churchil, 1978; Ward, 1974). This learning takes place through intergenerational influences, which are "within family transmission of information, resources, and preferences from one generation to the next" (Moore, Wilkie, \& Desrochers, 2017, p. 844).

Consumer socialization is an integral part of socialization and is defined as "the process by which young people acquire skills, knowledge, and attitudes relevant to their functioning as consumers in the marketplace" (Ward, 1980, p. 382). As children and adolescents observe the behaviors of their parents, they learn how to be a consumer (McNeal, 1987). Family communication is therefore important from the marketing point of view, as parents transmit their marketplace skills and knowledge to their children (Carlson, Grossbart, \& Stuenkel, 1992), who then adopt specific consumption patterns (Moore \& Moschis, 1981; Moschis, 1985).

The social learning theory identifies the following sources of influence (socialization agents): parents and relatives, peers, media, and schools (Moschis \& Churchil, 1978). While social agents such as media and peers play an important role in socialization, the family influence is the strongest. Parents and families are so important due to their primacy over children, being the first social agent, the frequency of contact, and power to grant rewards and punishments, as well as due to a strong predisposition to imitate behaviors of family members (Brim, 1966; Flouri, 1999; Grusec \& Davidov, 2007; John, 1999; McNeal, 2007; Mihalic \& Elliot, 2005; Moore, Wilkie, \& Desrochers, 2017; Moschis \& Churchil, 1978). Not only family plays an important role in the socialization process by exerting normative influence, but, according to childhood learning cognitive psychology, early learned concepts are strongly embedded in our semantic memory (Steyvers \& Tenenbaum, 2005).

Therefore, childhood experiences shape religious views, political affiliation and racial attitudes. Moreover, family influence mediates the effects of other sources of consumer learning (Kohler, Rohm, Ruyter, \& Wetzels, 2011; Moschis, 1985). Family not only teaches us about marketplace behaviors but also has a big impact on dietary choices (Kirk, et al., 2010), and some argue that it is the family environment that plays the most important role in shaping what and how we eat (Inglis, Ball, \& Crawford, 2005; Swinburn, Caterson, Seidell, \& James, 2004; Wansink \& Sobal, 2007). Childhood learning from 
parents have been shown to shape diet, consumption, brands preferred, and products consumed in adulthood (Connel, Brucks, \& Nielsen, 2014; Moore, Wilkie, \& Desrochers, 2017; Moore, Wilkie, \& Lutz, 2002; Richins \& Chaplin, 2015). Intergenerational impacts can be seen in the propensity to exercise, consume fruit, milk, vegetables, and the perception of diet, or being a picky eater (Moore, Wilkie, \& Desrochers, 2017), as well as can constitute an obesogenic influence (Moore, Wilkie, \& Desrochers, 2017; Reid, Worsley, \& Mavondo, 2015). This puts the family in a powerful position to potentially shape sustainable consumption patterns.

\section{Internalization of Consumption Values and Effects into Adulthood}

People model their behaviors on what they were exposed to as children (Mihalic \& Elliot, 2005) and lessons learned as children might shape their adult behavior. However, the question remains under what circumstances these effects last into the future. Young adults who live away from their families, experience total independence for the first time. As they develop autonomy and independence during college days, the influences previously imposed by the family lose their power (Brown \& Huang, 1995; Goossens, 2006).

Following the self-determination theory, we define autonomy as self-endorsement, which implies that an individual's consumption is based on their values (Deci \& Ryan, 2000). Therefore, he/she engages in specific behavior because they feel "I want to do this" rather than "I feel coerced to do this" by the environment and social norms. "The more the behavioral regulation has been internalized, the more it is experienced as autonomous or self-enforced" (Chen, et al., 2013, p. 1186).

As young adults go off to a college (or move out of the family home for other reasons), they start making their own decisions, without involvement of their parents (Goossens, 2006; Schwartz, 2000) and oftentimes tend to experiment and explore, consequently developing new food-consumption patterns (Arnett, 2000; Xu, Shim, Lotz, \& Alemida, 2004). Therefore, their consumption (just like other activities) becomes self-endorsed rather than controlled or pressured (Ryan \& Deci, 2000).

Self-determination theory differentiates between intrinsic and extrinsic motives. In the context of this study, intrinsic motive pertains to internal rewards, e.g. 'I am healthy', whereas extrinsic motives relate to external rewards and punishments, e.g. 'I will be approved or disapproved of'. The two motives characterize two different behaviors; the former, i.e., autonomous, self-endorsed behavior, and the latter, i.e., controlled behavior. (Deci \& Ryan, 1985; Ryan \& Deci, 2000). Self-endorsement, i.e. people regulating their behavior, is critical for maintaining specific behavior, not only because it gives individuals the sense of freedom and volition (Ryan \& Deci, 2011), but more importantly, because when people stand behind their actions they are more effective in their behaviors and stick to them (Ryan \& Deci, 2011). Self-endorsement also determines if the specific value or behavior is internalized. For instance, in the context of healthy consumption, Christodouildes, Michaelidou, \& Toroya (2012) show that intrinsic, rather than extrinsic motives predict the intention to eat healthy.

To describe the degree or stages of internalization, self-determination theory differentiates between four types of motive (1) external, (2) introjected, (3) identified, and (4) integrated (see Figure 1). The individual is motivated externally when he/she tries to: meet external expectations, obtain a reward, or avoid punishment. Introjected motive refers to the situation where an individual feels that he or she 'should' make a specific decision, but this feeling becomes internalized as internal pressure. Identified motive represents a deeper internationalization as the particular behavior is in line with individual's values and beliefs. The deepest type of internationalization is represented by the integrated motive when based on self-reflection and introspection, the regulation of particular behavior has become congruent with other values of the individual (Deci \& Ryan, 1985; Chen, et al., 2013; Rayan \& Deci, 2011). 


\section{FIGURE 1 \\ STAGES OF INTERNALIZATION}

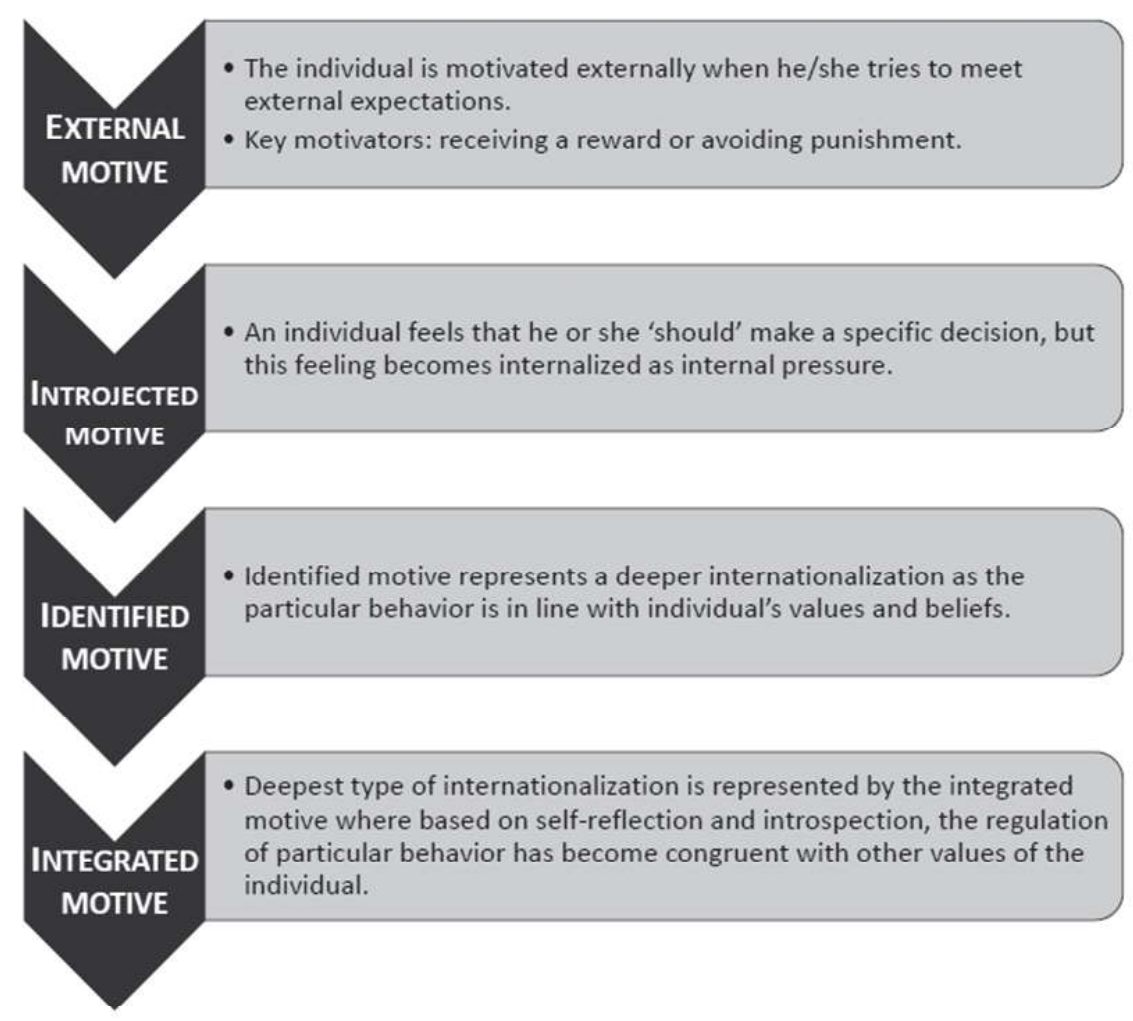

Parents and family are important socialization agents who transmit their values, behaviors, and attitudes to children. However, little is known about how family values influence the internalization of sustainable food consumption motives. In this article, we propose such a basis by focusing on variations in parents' values underlying sustainable food consumption as the antecedent of differences in food consumption patterns among their adult children.

\section{METHOD}

When choosing the methodological approach of this study, we recognized that the consumers' perspective should be the focus of attention, and thus we followed the psychology-centered, phenomenological approach that recognizes knowledge (here knowledge about consumption) as something acquired through the socialization process (Riley, 1996; Stern, Thompson, \& Arnould, 1998). We decided to conduct interviews as they are considered an effective qualitative means of collecting data about perceptions (Kvale \& Brinkmann, 2009; Qu \& Dumay, 2011) and expose the norms of behavior better than the behavior itself (Moisander \& Valtonen, 2006).

Face-to-face interviews with family members were conducted based on a semi-structured open-ended interview protocol (Fontanta \& Frey, 1994; Qu \& Dumay, 2011). This helped us uncover descriptions nested in a real-life context of day-to-day family life, to reveal the complexity of the socialization into consumption as a social phenomenon (Moisander, Valtonen, \& Hirsto, 2009). It also allowed us to use a laddering technique (Sinkovics, Penz, \& Ghauri, 2008; Qu \& Dumay, 2011). The informants were asked follow-up questions or were requested to elaborate on their initial response when it had the potential to yield more detail (Denzin \& Lincoln, 2005), which allowed us to uncover underlying factors that 
influence consumption behaviors. Thus, as desired in phenomenological studies, the semi-structured interview protocol offered more flexibility that would not be granted by structured interviews.

The interview protocol focused on three major areas: (a) the questions about family structure and family dynamics (e.g., who makes the purchasing decisions surrounding food, the influence of children and other family members on consumption and buying behaviors), (b) primary diet followed, (c) purchasing behaviors (e.g. criteria and underlying values for buying food), (d) family activities related to food (e.g., shopping, eating, cooking, or celebrating together).

Following Cornish and Moraes (2015), to analyze the actual food-consumption-related behaviors and avoid retrospective bias, we asked our participants to keep the receipts of three major grocery shopping trips over a period of two months. To have participants record their daily experiences around consumption in their own words (Corti, 2003), we employed open-format stimuli and suggested that they keep a diary where they report the rationale behind the purchases and consumption of the food, and their family experiences around food (e.g., shopping/cooking/eating/celebrating together). We received receipts and diaries a week before the scheduled interviews. Analyzing this content before conducting the interview allowed us to ask about specific food consumption behaviors and recognize factors such as motivations or family dynamics.

The families were recruited at three local restaurants (vegan, raw vegan, and a restaurant offering a variety of vegan and vegetarian foods alongside non-vegetarian meals). In this way, we were able to recruit 13 families. They then recommended others (an additional eight families) that would be interested in participation in this study. Interviewees received movie tickets to a local cinema as compensation for participation in this project.

We interviewed a total of 47 individuals from 21 families. In the first stage of the study, to ensure that we had a complete picture of the family dynamics surrounding food consumption behaviors, we interviewed at least two members of the same family, including at least one parent being the key dietary gatekeeper, and at least one adolescent child. 47 interviews were conducted at this stage (23 parents and 24 children from 21 families). These interviews were conducted separately with a parent/s and each child. In the second stage of the study, after two, and in some cases three years, we conducted follow-up interviews with 24 children (at least a year after the child moved out from the family house). To ensure the dependability and repeatability of the study, the interviews were tape-recorded (upon participants' agreement) (Sinkovics, et al., 2008) and transcribed (between 8-19 pages). The interview sessions lasted between one and two hours.

In the process of data analysis, we were continuously moving back and forth between the empirical data and notes. The data was read six times, and comparative method, categorization, abstraction, and scanning for unifying themes were employed to identify the recurring themes, as well as motivations and values underlying consumption decisions. This iterative process was continued until we gained the confidence of providing a thick description of the family dynamics in the adoption of the sustainable diet. Throughout the process, a graduate student provided member checks, which led to revisions. After the preliminary draft has been completed, ten informants ( 1 parent from each identified family type and six of their adult children including both those who persisted with sustainable diet and abandoned it) read the final draft of the findings and presented favorable comments confirming that the manuscript presents an accurate depiction of the consumption in their families.

\section{FINDINGS}

\section{Food Consumption Decisions}

In 12 out of 21 families, children were socialized towards sustainable food consumption throughout their entire life. In 9 families, this consumption pattern emerged later on due to parent's changing values and attitudes. In 5 cases, the family journey into veganism started when the children were in their early teens; in four cases they were in their late teens two-to-four years before leaving home for college. In the majority of the families, i.e., 17 cases, both parents are vegan. In 4 cases one of the parents does not follow a vegan diet, but the child/children followed the diet of a vegan parent (the dietary gatekeeper). 
The dietary keeper, who is the "person most responsible for purchasing foodstuff and cooking family meals (...) has a significant influence on what a family eats" (Reid, Worsley, \& Mavondo, 2015, p. 544,545). Most families agreed that there is one person (most often the mother - in 18 out of 21 cases) who makes crucial decisions about what is being cooked and what grocery items are bought. This does not mean that other family members have no influence on what they eat. They do, but these decisions refer mostly to their items of preference that account for $10-25 \%$ of all consumed items that are not enjoyed by other family members:

It is mom who cooks and makes the grocery list. We kind of always relied on her when it comes to our meals. But of course, we eat whatever we want. I like one particular brand of nuts, [Brother's name] likes a different one. And then there are some things that only I eat. I love raisins, everyone else in my family hates them. So I am the only one who eats them. I think it is like in any other family. [Family 3, Child 1-1 ${ }^{\text {st }}$ stage of interviews]

[Father's name] does most of the grocery shopping but it is [Mother's name] that cooks most of the meals, and she tells him what to buy. (...) Well each of us makes some things that we particularly like. [Father's name] has this particular type of vegan 'chicken' filets that he makes several times a week. No one eats them aside from him, so he just buys them and makes them for himself. [Family 8, Child 1-1 ${ }^{\text {st }}$ stage of interviews]

As shown in the above quotes, family members, including children, make autonomous decisions about specific items they eat. None of the children mentioned that they felt forced to follow a vegan diet. Many state that they feel that their food consumption decisions were made just like in the families of their non-vegan friends.

\section{Socialization Towards a Sustainable Diet}

Socialization towards sustainable food consumption takes place through joint activities. Celebrations and shared meals, collective rituals surrounding brands, and leisure activities (Bradford \& Sherry, 2015; Schau, Muniz, \& Arnould, 2009; Thomas, Price, \& Schau, 2013; Weinberger, 2015) constitute consumption rituals, which are both a reflection of culture and play an active role in the construction of culture (Wallendorf \& Arnould, 1991). Rituals also build reference group association (Cialdini \& Trost, 1998), and create a sense of family culture and family identity as reflected in the quotes below:

I knew that this interview was coming up and talked to my friends from [the name of the school attended] how they learned to eat what they do (...) I think we came to a conclusion that this is like an intangible process. We just learned what to eat since we were small and it just makes sense and seems natural [the friends are meat eaters] because you just do it with your whole family and you sort of take it for granted and it is just a part of who you are. [Family 5, Child 2-1 ${ }^{\text {st }}$ stage of interviews]

I do not think I felt particularly different just like any other kid when they went to celebrate Christmas, I would celebrate it with my family, we would just eat something else. We are just like any other family we have our favorite foods for birthdays, my mom knows that I love the raw blueberry cake so that is what we always have for my birthday, and [sister's name] loves the chocolate mint cake so that is what she gets. Food is a part of our family just like any other family. I guess I never thought of it before, but that is how it is.

[Family 11 , Child $1-1^{\text {st }}$ stage of interviews]

We have this little family tradition that when someone comes back from a trip, for instance, when I came back from the summer camp or school trip, we sit together and 
talk about the trip and have a 'golden milk drink' and the coconut cookies. It is just something sweet that makes you feel that everyone was waiting for you to come back, it is nice to have this kind of family thing. [Family 18, Child 1-1 ${ }^{\text {st }}$ stage of interviews]

This [the family rituals] gave these cookies a special meaning, and you get kind of emotionally attached to it. When I saw the coconut cookies at a local farmers market, it made me miss my family and think about them, and I bought them even though I knew they are not going to taste like mom's do. (...) Now, whenever I come back from college, she still makes the cookies, and we sit together as a family. It is just 'our thing'.

[Family 18, Child 1-2 ${ }^{\text {nd }}$ stage of interviews]

Food-consumption-related rituals may include a joint family dinner in the evening, meals eaten at family celebrations, and holidays such as birthdays, Christmas, Thanksgiving, etc. Thus, "products used in ordinary [not sacral] rituals can take on emotional meaning (...) becoming symbolic" (Gentina, Palan, \& Fosse-Gomez, 2012, p. 116).

Because of repetition "through collective engagement in consumption rituals", group members reinforce intragroup relationships and the boundaries of the group (Weinberger, 2015, p. 378). Therefore, the participation of family members in collective rituals makes the family members more emotionally connected (Collins, 2004). Through rituals involving 'family time', sharing of stories, the family gains its own distinct identity (Epp \& Prince, 2008).

Family communication involves both verbal communication and purchase-oriented behavior. Daily interactions shape what family members are expected to do, consume, and how they are expected to behave (Ronka \& Korvela, 2009). This effect is especially seen regarding mundane tasks including shopping, cooking, dining, going out, and leisure (Grusec \& Davidov, 2007), as reflected in the following quotes:

You know... I think it is like with any parents where they tell you what do or not to do. I remember when I was maybe in the primary school and went grocery shopping with dad and I pointed at some cheese crackers... I do not really remember what that was, and he said no we do not buy this because it has dairy in it. When I asked what that is and why we cannot eat it he said it is a milk that a little cow is supposed to drink, so it is not good for us, he also scared me that I would grow little hooves like a baby calf.

[Family 6, Child $1-1^{\text {st }}$ stage of interviews]

One day I came back crying because kids were calling me a grass-eating rabbit. I do not remember how old I was. My mom showed me a video of rabbits and asked if I prefer to be a grass eating rabbit or if I would prefer to eat that baby rabbit in the video. Then I started crying that I do not want to eat the rabbit because it was really cute. We then talked about the animals and that they are alive and feel just like we do so it is not a good thing to harm them. She also made it clear that if I wanted to eat meat I can, I would just need to prepare it myself because she does not want to participate in a murder of an innocent being.

[Family 1, Child $1-1^{\text {st }}$ stage of interviews]

My parents always took pride in their lifestyle including their diet. I feel they have looked down at people who would eat at McDonald's or other fast food places as they considered that not taking care of yourself and putting this kind of stuff into your body is not being progressive as if you were from the $20^{\text {th }}$ century... you know what I mean. I remember a couple of times when I bought barbecue chips and ate them in secret, and the second time my mom found the package in a trashcan, and she would ask me 'do you really want to be like those people?' I felt very ashamed.

[Family 15, Child 1-1 ${ }^{\text {st }}$ stage of interviews] 
I remember very vividly when I wanted to have my birthday party at McDonald's just like all the other kids in class, and my mom was like 'Do you really want to be like those fat people on the TV', we sat down that week and watched 'Supersize me' movie. I really hated that I could not have that one party like all the kids because we were supposed to watch our weight. [Family 21, Child $1-1^{\text {st }}$ stage of interviews]

As shown in the above quotes, family members consciously and unconsciously communicate certain norms and expectations to each other. Moreover, at a cognitive level, children learn by observation:

You know as a child you just look up to your parents, I remember a time when I wanted to be just like daddy, and if he ate a particular thing I would want to eat it too, I would eat the whole plate and ask for seconds even though it did not taste good to me, I just wanted to do what he did... Of course, you know... I am no longer like that, but I guess we learn by watching our parents, [Family 15, Child $1-1^{\text {st }}$ stage of interviews]

Family communication is defined here as "parent-child overt and cognitive (nonverbal) communication process and patterns of interaction" (Moschis, 1985, p. 900). Parents' influence on children can be direct or indirect. Direct influence involves norms enacted through the system of rewards and punishments, which can include affection or psychological punishments (Moschis, 1985) as represented in the following quotes:

My father could not contain himself about how proud he was of me for making the right choice. Seeing him like this was really priceless. I think this made us all feel even closer as a family, it felt as if we were really special... or better.

[Family 1, Child 2-1 ${ }^{\text {st }}$ stage of interviews]

I knew that when I told my mom that of course, I won't be eating the animals because it was bad for our body she was very happy and she was proud of me for 'making the right decision', so (...) If my friends were tempting me, I would remember that I did not want to do something against her (...) I wanted to avoid conflict.

[Family 11 , Child $1-1^{\text {st }}$ stage of interviews]

I think the biggest problem was the peer pressure and I guess before I really was able to differentiate what is good or bad myself. Thinking of how disappointed [Mother's name] would be in me if I succumbed to that pressure and went against basic values that we shared as a family would have been the greatest punishment.

[Family 8, Child 2-1 ${ }^{\text {st }}$ stage of interviews]

As represented by the above quotes, direct influence involves both overt and cognitive communication about food consumption, as well as rewards and punishments. Moreover, certain rules might be encouraged through rewards and punishments system. These include psychological punishments or affection.

Indirect influence, on the other hand, lies in the mediating effect family communication has on other socialization agents (Moschis, 1985), as reflected in the quotes below:

I think I have not even realized that my family was different until I went to primary school. There I got bullied by kids. I remember them calling me a 'carrot girl'. When my grandma came to pick me up I was in tears (...) we later talked about it also with my parents and discussed why we eat this way, and I felt it made sense and they gave me some arguments to give to the kids. It got better over time.

[Family 18, Child $1-1^{\text {st }}$ stage of interviews] 
(...) They poked fun at my lunch box. I remember there was a time when that would be an everyday dinner conversation, but my parents had good arguments, and while I did want to be like other kids I also did not want to be a bad person and did not really want to hurt

animals. Anyway, after some time everyone got used to this, and I became just a part of the team. Some friends even wanted to try some of my things because my lunchbox was always colorful and theirs looked kind of sad and boring actually.

[Family 1, Child $1-1^{\text {st }}$ stage of interviews]

I think over time all these stupid encounters became family jokes. My parents would often come back from work and shared jokes about how colleagues at work commented on the color of their smoothie or made fun. (...) So we had a lot of stories. At some point, I actually treated this as a badge of honor if I could come home and have a story about the carnivore bullies. (...) Seriously at this point, I no longer care, and everyone at school knows that I am that 'vegan guy'. Actually, some girls are really interested in that.

[Family 3, Child $1-1^{\text {st }}$ stage of interviews]

The indirect influence was reflected in conversations with peers at school and communications in media (and advertising) being discussed with parents and other family members at home.

\section{Family Types}

We have identified four family types. Each family type represents a different journey to food sustainability and varying motives for sustainable food consumption: (1) Healthoholics, (2) Tree-huggers, (3) Mom is always on a diet, and (4) Keeping up with the Joneses. In what follows, we will describe key characteristics of these family clusters.

\section{Healthoholics}

Five families represent the group of 'healthoholics' (health-conscious family category). As one of the family members described, his family is 'in search of the elixir of eternal life'. While some of the parents in this group have a background in health (medicine, pharmaceutical, homeopathy, physiotherapy, acupuncture, dietetics), others had no educational background in health-related disciplines, but were passionate about a healthy lifestyle as represented in the following quotes:

You know when you look at those videos or the pictures... how can this cow, which is fed all these antibiotics and hormones, and looking so much like a monster, and it never saw the sunlight or ate grass be healthy? ... you know how anyone can think that this is healthy for us to eat? [Family 20, Parent 1]

I have always been passionate about health and longevity and even when I was a teenager I was fascinated by all the things we can do to nourish ourselves and extend our lifespan. Later on, I read many different books and articles and just decided that this [vegan diet] is a way to go. Looking at my colleagues who are the same age... I do not want to sound judgmental, but it looks like this is working for me much better than their carnivore diets for them. (...) Of course, having a family... and my wife shares the same opinion on this... we want to instill the same values in our kids.

[Family 19, Parent 2]

When my mother died of cancer, I started paying more attention to my health and introduced many positive changes. Later I studied to be a dietitian so with that I was exposed to many studies on nutrition and based on that decided that vegan diet is the best option if I not only want to avoid cancer but also enjoy health. When I met my husband, he was hesitant at first, but I was the one cooking (...) [Family 12, Parent 1] 
My father was a Chinese medicine doctor, so I grew up with a more holistic approach to health and body than most people. Even though my career has nothing to do with health, the childhood experience motivated me to pay attention to what we eat and make sure that it is the healthiest diet possible. I did not grow up in a vegan family but based on my own studies I came to the conclusion, and in today's world, this is our best shot at longevity. [Family 4, Parent 1]

As represented by the above quotes, the dietary choices of this family type are driven by the motivation to maximize the health and fitness of their family. The dietary gatekeeper, i.e. key decisionmaking family member(s) tries to keep up with the current research and reports about a healthy lifestyle. They chose a vegan or a raw-vegan diet based on extensive research through reading articles and books about nutrition, even when their professional lives are unrelated to these subjects.

This family category pays close attention to what they buy, e.g., lists of ingredients, origin (organic) and health claims made by the producer:

I bought this coconut milk because it does not have any bad additives; I think this is the only brand we found that is relatively pure (...) Yes I check the ingredients of everything we buy. [Family 6, Parent 1]

I am very careful and check all the labels and do little research about them. For instance on pretty much everything you can see 'Natural' well that is something that you can put on everything. Everything is natural you could put 'natural' label on CocaCola. So... we try to buy only organic certified products, and before I fall for a label I always do my research and check what it stands for because sometimes producers just come up with something that sounds green and there is no certification supporting it!

[Family 20, Parent 1]

This customer category can be persuaded to buy a new product if the advertising content focuses on informative appeals that emphasize health benefits and longevity. Therefore, they avoid 'vegan junk food' or highly calorific vegan meals. At the same time, they are very knowledgeable about different labels and not susceptible to greenwashing claims. They can be found at yoga studios, health and organic stores, and chiropractor offices. They trust the owners of these companies and can be influenced by them to a bigger extent than by other 'experts'.

Tree-huggers

There were six ethically-driven families. They have chosen a vegan lifestyle based on their concern for the environment and animals:

I work in academia, and we had a project on environmental impacts of agriculture, of course, I could not continue with a traditional diet knowing that the plant-based vegan diet with locally sourced ingredients has the lowest negative impact on the environment, so that is how it started and that is what motivates me. And of course, I do not want to eat an animal that suffered so much. I think if people were not so removed from their food sources and really saw what is going on on those farms we would have many more vegans.

[Family 7, Parent 1]

When you watch the videos and see how the animals are treated... Once I learned about this... I just... I just could not look at myself in the mirror knowing that I am contributing to this. And I feel I would have failed as a parent if I taught my children that it is ok to 
mistreat and murder any living beings in this way. I have never second-guessed my decision on this. [Family 18, Parent 1]

I think we are the most egoistic of species, look at what we have done to our planet and what we are leaving for our children and grandchildren. Even though I know that mine and my family's actions alone have a very small impact in the grand scheme of things, I could not sleep at night knowing that I am contributing to this madness.

[Family 3, Parent 1]

As the quotes above show, the ethically driven family recognizes that a vegan diet has the lowest environmental footprint. Moreover, they do not want to contribute to cruelty toward animals. Their consumption behaviors are based to a lesser extent on the health implications than environmental impact, as indicated by the following quotes:

Oh yes I know there are many that say this is not healthy for humans, seriously would you really kill someone. I prefer to live a bit shorter and have a clear conscience.

[Family 14, Parent 1]

I mean ... I really... there was a time when I really loved milk like I would drink a gallon a day. That is until I read about the treatment of diary cows. How they separate baby cows shortly after they are born, I mean what if they separated you from your child and forcing you to be a milking machine. Sorry no... I just cannot contribute to this.

[Family 8, Parent 1]

The way I was taught was do not do to others what you would not want to be done to you, whether it is a human being or any other living being. So to us, killing animals or treating them as I said, this is just like a crime. [Family 1, Parent 1]

(...) Oh if I did something like that [ate meat] my parents would be really disappointed just like any parent when their child commits a crime. (...) Really being a good person matters more than what my friends at school would say, it is their conscience.

[Family 1, Child 1, $1^{\text {st }}$ stage of interviews]

The quotes above show that the food consumption in this family is value-driven, and this aspect of life is very important as the dietary choices are seen in categories of being good or bad, and lead to perception of oneself as a 'good person' or a 'bad person'. Unlike a health-conscious family, the treehugger family eats 'vegan junk-food'.

Keeping up with the Joneses

There were six families in the 'Keeping up with the Joneses' category. This type of family is influenced, to a great extent, by consumption patterns of their working and social environment:

Well, we really wanted to move to this new schick green neighborhood.... And we paid a premium for it... The main reason was that we wanted the children to grow up with the freedoms we had and did not want to worry about them running around the block etc.

(...) We were rather careful and conscious about what we were buying and eating, but of course moving in here adds... I do not want to say it adds pressure, but you know... there are certain expectations. And especially when you are new, people stare into your grocery basket. [Family 5, Parent 1] 
When we had [son's name] birthday party, and he gave out the invitations, I got ten phone calls about his friends' dietary restrictions. They were mainly about eating only organic, no meat, no dairy that is not from free-range animals, being vegan not drinking, e.g., packaged juice which has sugar and a dozen other requirements. This is the neighborhood we live in. [Family 9, Parent 1]

When I went for lunch with a next-door neighbor and ordered a salad topped with parmesan cheese, our lunch turned out into an hour-long lecture about the suffering of animals. [Husband's name] had a similar experience with his new poker buddies. I felt as if my neighbor saw me as an uneducated savage. She followed up the lunch with sending me some recipes... and called the next morning to invite me to join her for shopping at a farmers' market. [Family 13, Parent 1]

As reflected in the above quotes, the families in this category live in the geographical regions or neighborhoods characterized by many health-conscious or environmentally conscious people. They do not have as long a history of eating a sustainable diet as the previous two types. This is how they elaborate on their motivations:

You know our social circle and we just consider it to be rather uneducated or primitive not to acknowledge the impact human race has on this planet (...) It would be social suicide if I bought leather sandals and [Daughter's name] had... I do not know... cheese crackers in her lunchbox. (...) That is the trend here... We just want to be progressive (...) and being vegan is a part of that. [Family 15, Parent 1]

At [the name of the company] everyone is very 'green', sometimes even fanatically. When I started out and brought my lunch to work and got the looks and comments I knew that to be accepted I need to conform to a specific lifestyle (...) to be honest I would not have been able to climb the ladder here if I did not show I was progressive, if it wasn't for these changes. (...) You need to show you know that you are up to date with the current trends. [Family 16, Parent 1]

'Keeping up with the Joneses' families adopt the vegan diet because it is trendy in their social circles, as represented in the above quotes. While they enjoy the health benefits of the vegan diet, they are more concerned with how others perceive them and feel that the specific consumption behavior determines their social status.

Mom is always on a diet

In our four 'Mom is always on a diet' families, the decisions about food consumption are shaped by weight goals or concerns of one of the decision-makers in the family (the dietary gatekeeper), as described in the following quotes.

I have always had problems managing weight, and I do not want my daughters to have the same problem. That is why we are on a strictly vegan diet. I have tried a lot of other diets before, and this is the only one that works for me for years now. [Family 11, Parent 1]

It's been a few years now, this is the only diet that keeps my weight where I want it to be. I read a lot and always incorporate more vegan superfoods and supplements, I Iike experimenting. This lets me have variety and not get bored as on other diets I have been on because there are so many different smoothies, salads, etc. you can try. (...) I do not 
want my daughter to be obese so yes she has to follow it, and she knows and understands why. [Family 2, Parent 1]

I do not want my daughters to be fat. We all know how the society treats fat people and how it will affect their career and relationships. That is why I have been watching my weight since I was ten years old. (...) Veganism is the easiest way to control them [the daughters] because they know exactly what to eat and not to eat, and they know it is for their best. [Family 10, Parent 1]

The food consumption choices of the dietary gatekeeper are shaped by the current trends and reports of the next new 'miracle' superfood or supplement. While the 'health-conscious family' did much research about the nutrition and health claims of the products, this family is very susceptible to different labels and health claims. Also unlike the health-conscious family, this family's tenure in sustainable consumption is relatively shorter.

\section{Internalization of Sustainable Consumption Values}

Young adults, who live away from their families and experience more independence for the first time in their lives often tend to experiment and explore different lifestyles and, as a consequence, develop new food consumption patterns (Arnett, 2000; Xu, Shim, Lotz, \& Alemida, 2004). As they develop autonomy and independence during their college days, the influences previously imposed by the family lose their strength (Brown \& Huang 1995; Goossens, 2006). Thus, when the previously established behavior or diet appears to be difficult to maintain, they question it:

As I am waiting at the [city name] train station, I have a choice: a cheeseburger that will keep me full until the dinner for a fraction of the cost of a smoothie or a salad, which cost three times more... and I will be hungry perhaps after one hour. Not to mention it is not even the end of the month, and I am short on budget.

[Family 11 , Child $1,2^{\text {nd }}$ stage of interviews]

As presented in the above quote, which is representative of experiences of all interviewed young adults, low-income consumers face more restrictions when making food consumption decisions and often have to compromise on the quality or nutritional value (Chung \& Meyers, 1999; Curtis, 2000; Hamilton, 2009).

Aside from financial difficulties, other factors are an important barrier to continuing the diet:

(...) not to mention all the problems when you go out to eat and many restaurants have no vegan options, or all you can eat is a salad that has five calories.

[Family 8 , Child $1,2^{\text {nd }}$ stage of interviews]

Going out with non-vegan friends is a nightmare if everyone wants to go to a fast food restaurant or a steakhouse (...) after some time people stop inviting you because they do not want to look for a place or feel bad that you have nothing to eat.

[Family 14, Child $1,2^{\text {nd }}$ stage of interviews]

Of course, that is the thing people notice about you, and some make jokes, it is nothing different than in the primary school really (...) Oh, and all the people telling me that I am slim enough and do not need to watch my calories. It gets annoying, and I hate that people see it in this way. They do not understand I was vegan not because of my weight. [Family 4, Child 1, $2^{\text {nd }}$ stage of interviews] 
The above quotes show that young adults face peer pressure and other difficulties characterizing vegan diet (e.g., eating out or traveling). While they lived at home, the content of peer communications and other influences were discussed with other family members (see the discussion on the indirect parental influence above), but that is not the case when they move out from their family home.

Perceived barriers affect the individual's perception or opinion about the cost of specific behavior (Fila \& Smith, 2006; Rosenstock, et al. 1994), which determine whether we will engage in a specific behavior or not (if we find it too costly). All young adults in this study agreed that the vegan and sustainable food consumption has a much higher cost than the mainstream diet. However, the responses to the above-mentioned situations differed dramatically when we compare young adults from families driven by different motives. Despite these difficulties, some young adults remain faithful to the vegan diet they were socialized into, whereas others change their consumption patterns. What makes these few continue with the sustainable diet is the key question we posed.

Internalization is a process through which "individuals acquire beliefs, attitudes or behavioral regulations from external sources and progressively transform those external regulations into personal attributes, values, or regulatory styles" (Grolnick, et al. 1997, p. 139). Self-determination theory differentiates between four types of motives (1) external, (2) introjected, (3) identified, and (4) integrated. The following quotes represent different types of motive or stages of internalization.

\section{(1) External motive}

Of course, as a small child, I just ate like any other child... whatever my parents would put on my plate... without thinking about it. [Family 18, Child 1, $2^{\text {nd }}$ stage of interviews]

I would not want to anger my mom and be punished to go to my room if mom was angry that I was a picky eater so I would eat it. [Family 21, Child 1, $2^{\text {nd }}$ stage of interviews]

At first, when the motive is external, as reflected in the quotes above, a child is motivated by external contingencies including parental requests, rewards, and punishments.

\section{(2) Introjected Motive}

... At that point, I knew we were a vegan family, so that is what we ate.

[Family 13, Child 1, $2^{\text {nd }}$ stage of interviews]

It was a part of being a family, every family has its own rituals. So I did not really think that much about it. I did not feel forced, but I also did not decide to be vegan, I did not really consider it to be up to me. [Family 18, Child $1,2^{\text {nd }}$ stage of interviews]

This is followed by a stage when we talk about introjected motive, when, as reflected in the above quotes, the child is motivated internally, i.e., he/she accepts the external rules as their own but still sees his/her behavior as something that is a subject to external control.

\section{(3) Identified Motive}

I do want to be healthy, and I think this keeps me in good shape.

[Family 19, Child $1,1^{\text {st }}$ stage of interviews]

I just really love the animals and cannot imagine eating one and playing with another an hour later, I do not want to be a hypocrite (...) I do not feel being forced at all.

[Family 7, Child $1,1^{\text {st }}$ stage of interviews] 
I want to follow basic ethical principles and being vegan was a way to do so. I am at the age when I can make my own decisions, and my family knows that

[Family 18, Child $1,1^{\text {st }}$ stage of interviews]

In the next phase, i.e. when the motive is identified, as reflected in the quotes above, the children perceive the specific behavior as something that helps fulfill their own objectives and recognizes their right to choose.

\section{(4) Integrated motive}

You know how it is in college, you can do all those things when your parents are not around that you perhaps normally would not (...) and re-think many things about your own identity (...) but this [eating vegan] it is at my very core and even though it is much more difficult than it was when I lived with my parents. Oh so much more difficult! This is not going to change because it is a part of what I truly believe in.

[Family 3, Child 1, 2nd stage of interviews]

I know I want to be a good person, and I deeply care about our planet. More so, I care about the wellbeing of all animals, so that [being vegan] is just a part of who I am. (...) I think that moving out and living on my own really gave me an opportunity to crystalize it in my head what I want and there is no doubt in my head that that is who I am and want to remain. [Family 18 , Child $1,2^{\text {nd }}$ stage of interviews]

In the last stage, when the motive is integrated, as reflected in the interview excerpts above, the children identify with specific behavior and perceives it as a part of one's self, and considers it as a part of their own values.

The children, who before moving out (at the first stage of the interviews) have not been at least at the $3^{\text {rd }}$ stage of the internalization process (i.e. identified motive), abandoned the food consumption pattern in which they were socialized between two months and one year after moving out from the family house, and did not eat vegan at the time of the second interview which took place two-to-three years after they moved out, due to the obstacles discussed below.

I am sorry, but with a limited budget, as a student, I just could not afford to do that. [Family 6, Child $1-2^{\text {nd }}$ stage of interviews]

You know, I wanted to go out with friends and just enjoy being a student without dealing with the peer pressure and all that. [Family 13, Child 1-2 ${ }^{\text {nd }}$ stage of interviews]

I did not want the only thing the guy remember about me after a date is that we had to spend 30 minutes looking for a place I could eat at, or that I ordered salad and reduced it from 10 to 3 ingredients. I just wanted a normal life every student has.

[Family 4, Child $1-2^{\text {nd }}$ stage of interviews]

In some cases, when children did not agree with parents values, they were very quick to give up on the vegan diet:

I really hated that I could not have that one party like all the kids [birthday party at McDonald's] because we were supposed to watch our weight. It was just one party after all. (...) For a long time, I thought'once I get out of this house [move out] I am gonna eat McDonald's every day. I, of course, do not do that, but I also do not follow the family 
diet anymore (...) I still try to eat healthy, but I do not believe you have to be so draconian about it [Family 21, Child 1-2 ${ }^{\text {nd }}$ stage of interviews]

I feel my mom has been really obsessed about her weight and I do not appreciate her obsession with my own body and my own weight. I really do not care about it, and I am so happy not to listen to all the comments that I put on half a pound last week. (...) no, I do not see myself following this diet in the future [Family 10, Child $1-2^{\text {nd }}$ stage of interviews]

I still have this vivid memory of when me and [Sister's name] decided to have a real adventure and go to the McDonalds to try the chicken nuggets. We carefully planned everything and made sure that our parents were not going to be anywhere nearby. As we approached it and stood in front of the doors with excitement in our eyes and huge smiles we noticed my mom's friend on the other side of the pavement. We were terrified. We knew that if mom learned about this, she would be so so sad. I think she would have even preferred us to have it at home but to have it outside where someone else would see, she would see it as a real betrayal... we often heard her say: 'what will people say?!' (...) Now I feel she cares about it more than what her own family thinks (...) when I come home for the holidays I pretend that I am vegan. But I am really happy to be 8 hours away and eat whatever I want. [Family 15, Child 1, $2^{\text {nd }}$ stage of interviews]

The above quotes show that the consumption values which are not internalized become rejected and may even cause resentment when children do not agree with the values presented by parents.

In our research, only children who fully internalized the sustainable consumption values and were at the level 4 of the internalization process (i.e. integrated motive) continued eating vegan after 2-3 years moving out from the family house (at a time of the second round of the interviews) and declared that they were determined to keep it up.

Yes, it is difficult, it is difficult to go out with a girl you just met and be so picky when you are ordering a simple meal. But, this is who I am and these are my values. So if someone does not respect that... I mean then they are not for me.

[Family 14, Child 1, $2^{\text {nd }}$ stage of interviews]

So, as I already said, it is much more expensive. But, this is not something I can compromise on ... like would you eat your dog if you were hungry? I do not mean you... I mean many people would not... and that dog is like any other animal to me... I mean any other animal is like that dog to me. [Family 1 , Child $1,2^{\text {nd }}$ stage of interviews]

It [being vegan] causes many awkward social interactions. (...) But if someone really accepts you and they are your real friends they will just take me like that. If they do not, they are definitely not worth committing such a sin and going against what I truly believe in. [Family 7, Child 1, $2^{\text {nd }}$ stage of interviews]

Intergenerational impacts have a very strong influence on values (Moore, Wilkie, \& Desrochers, 2017), which is exhibited in the above quotes. Only integrated and fully internalized motives, which become one's core values and self-endorsed goals (see figure 2), protect the young adults from all the temptations and obstacles and ensure that they will continue the specific food consumption pattern they were socialized into. This was the case for all 6 tree-hugger families (and 8 young adults within these families), and one child from one healthoholic family ( 1 out of 5 families representing this family category). 


\section{FIGURE 2 \\ INTERNALIZATION OF SUSTAINABILITY VALUES}

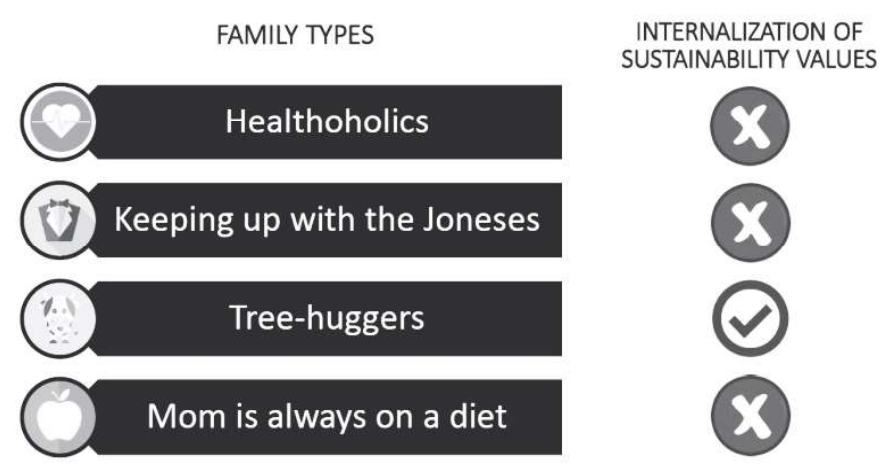

\section{DISCUSSION}

To answer the question posed at the beginning of this paper as to the role of a family in the socialization towards sustainable food consumption we analyzed over 70 interviews, grocery shopping receipts, and consumer diaries from 21 families. Families were grouped based on similarities in general food consumption tendencies and values underlying their dietary decisions. Through this analysis, this article details four types of inductively derived families. For each of these families, the article uses consumer socialization theory and self-determination theory to analyze and articulate long-term implications for sustainable food consumption of their adult children. It thus provides an answer under which circumstances sustainable consumption values are internalized and vegan diet is continued into adulthood.

As the family is a very interdependent system (Moore, Wilkie \& Desrochers, 2017), family members conform to dietary choices of the family to prevent conflict (Hamilton, 2009; Holdert \& Antonides, 1997; Hasford, Kidwell \& Lopez-Kidwell, 2018). Moreover, the family identity is reinforced by family routines and rituals (Epp \& Price, 2012; Grusec \& Davidov, 2007; Moore, Wilkie, \& Desrochers 2017; Ronka \& Korvela, 2009). This interdependence and family identity maintained by family consumption rituals are evident in studied families and resulted in children conforming to the dietary choices of their parents across different family types while they lived with their parents. Moreover, consistent with the resources' theory (Inglis, Ball, \& Crawford, 2005; Turner \& West, 2006; Wansink \& Sobel, 2007), the dietary keepers, who were attributed power over family food consumption decisions, influenced the dietary choices of their children.

However, as we show, neither the conditions of interdependence and shared identity, nor the power of the dietary gatekeeper, are enough for the socialization effects to last into adulthood. We thus show that the power-oriented resources approach, which is the foundation of many family studies (Inglis, Ball, \& Crawford, 2005; Turner \& West, 2006; Wansink \& Sobel, 2007), cannot explain the long-term socialization into consumption. Mere compliance when living with parents does not mean that sustainable food consumption has been fully internalized. The effectiveness of the socialization towards sustainable food consumption requires more than just complacency combined with the parental demands. As we show in this study, for internal adaptation to take place, the sustainability values have to be integrated into one's own self (Moore, Wilkie, \& Desrochers, 2017). Appropriate conditions, including self-endorsement and internalization of the values, need to be in place for this integration to take place, to ensure that sustainable food consumption is continued in adulthood.

Therefore, the self-determination theory offers the answer to the question posed in this research as we show that self-endorsement guarantees better accomplishment of the goal, consistent with other longitudinal research on self-endorsed goals (see Sheldon \& Elliot 1999; Smith, Ntoumanis, Duda, \& Vansteenkister, 2011). Even though, as we show, the success of the long-term socialization towards 
sustainable food consumption lies in the internalization of sustainability values, little attention has yet been given to this topic. Thus, we expand this theoretical approach on the premise of sustainable food consumption and show that self-endorsed consumption is the key to internalizing sustainable values. As our research shows, the success of the socialization towards sustainable consumption depends on it being driven by ethical values (tree-hugger families), rather than self-centered motives (e.g. being healthy, progressive, or weight goals). Only ethical values and perciving the consumption behaviors in terms of them being good vs. bad, or as a sign of being a good vs. bad person, are internalized and become integrated motives. Only integrated and internalized motives result in the vegan diet becoming selfendorsed, which protects young adults from all the temptations and obstacles they endure upon moving out of the family home, and ensure the long-term continuation of the food consumption behaviors they were socialized into.

\section{CONTRIBUTIONS}

\section{Theoretical Contributions}

Given a limited stream of research on the topic, our understanding as to why consumers engage in sustainable food consumption remains largely elusive, even with the proliferation of pro-environmental campaigns. While much research has focused on purchasing green products by individuals (De Groot \& Steg, 2007; Griskevicius, Tybur, \& Van den Bergh, 2010; Lin \& Huang, 2012; Luchs, Naylor, Irwin, \& Raghunathan, 2010), fewer studies have focused on family sustainable food consumption decisions, and how the family consumption of a sustainable diet shapes long-term food preferences and eating habits of young adults. Surprisingly little attention has been given to the topic of internalization of sustainability values. What has been lacking in prior consumer behavior research is a theoretical basis for understanding distinctive values underlying family socialization towards sustainable food consumption and how they influence the internalization of sustainable consumption values into adulthood. To address this gap, we identify the factors in family socialization that affect internalization of the sustainable food consumption.

Therefore, this study contributes to the existing knowledge in three ways. First, as diet is a major factor in sustainable development (Geeraert, 2013; FAO, 2006; UNEP, 2010), understanding the determinants of long-term sustainable consumption is of paramount importance for society, families, and policy makers. Both food production and consumption are important issues for sustainable development. Despite food consumption patterns having a significant influence on our environment, this constitutes an underdeveloped component in global sustainability debates (Geeraert, 2013). We contribute to this understanding by studying why people decide to eat a vegan diet.

Second, although past studies have examined motives underpinning environmentally friendly purchases, there is still a gap in the literature with regard to family socialization towards sustainable consumption. Our framework, with its focus on the family, addresses this gap within the sustainability domain. Shifting focus to the family highlights the importance of socialization towards sustainable consumption, reflecting that some children begin their lives being conditioned toward environmentally friendly behaviors. We contribute to this discussion by identifying different family motives and rituals surrounding this process and provide a theoretical foundation for understanding family differences in socialization towards sustainable food consumption.

Third, while previous literature focused on the socialization of children and adolescents (e.g., Wut \& Chou, 2013; Ekstrom, 2006; Harris, Gordon, McKontosh, \& Hastings, 2015), a longitudinal approach has been largely overlooked by previous research (John, 1999). While the previous studies examined differences in parents' consumer socialization tendencies and implications for children's autonomy, they did not look at the long-term effects of various socialization patterns towards sustainable food consumption. Therefore, this study goes beyond prevalent child development stages and builds on the self-determination theory to investigate the long-term impact of this socialization of young adults who no longer live with their families and compares the impact of different family socialization processes on how lasting the effects of the socialization are. Our study expands the self-determination theory to the context 
of sustainable consumption as we show that self-endorsed food consumption is the key to internalizing sustainability values and long-term socialization towards this type of food consumption.

\section{Practical Implications}

This research also has implications for marketers and will help them improve their communication campaigns directed at families and young adults. We show, against general preconceptions, that vegans are not a homogeneous customer group. As family culture is more diverse, new factors that influence consumption behavior create new challenges and opportunities for marketers. Not only parenting styles differ (Carlson, Grossbart, \& Stuenkel, 1992), but also socialization towards sustainable food consumption is unlikely to be uniform as consumers vary in their motivations for engaging in 'green' consumption.

From a business standpoint, this study provides an initial examination of consumer socialization in a sustainability-oriented context. Identified family types could provide a means of segmenting parents across international boundaries, and social campaigns could be used to ensure internalization of sustainable food consumption patterns.

The following consumer segments should be targeted with different marketing and advertising strategies (See Table 1). The 'healthoholics' are very knowledgeable about different labels and not susceptible to 'greenwashing' claims. They can be found at yoga studios, health and organic stores, and chiropractor offices. They trust the owners of these companies and can be influenced by them to a bigger extent than other 'experts'. They can be influenced by informative content which is supported by solid research about health implications. Advertising with emotional appeals easily persuades the 'treehuggers', (e.g., ads emphasizing concern for the environment, compassion toward animals), rather than informative, health-oriented ads. The 'keeping up with the Jones' family can be appealed to with emotional appeals related to status. The 'mom is always on a diet' family can be targeted by emotional appeals stimulating positive emotions. This family is also the most susceptible to dietary changes and changes regarding consumed products. 
TABLE 1

MANAGERIAL IMPLICATIONS

\begin{tabular}{|c|c|c|}
\hline FAMLLY & KEY CHARACTERISTICS & MARKETING IMPLICATIONS \\
\hline Healthoholics & $\begin{array}{l}\text { - Passionate about a healthy lifestyle; } \\
\text { - Keep up with current research and reports; } \\
\text { - The motivation to maximize their health } \\
\text { drives dietary choices. }\end{array}$ & 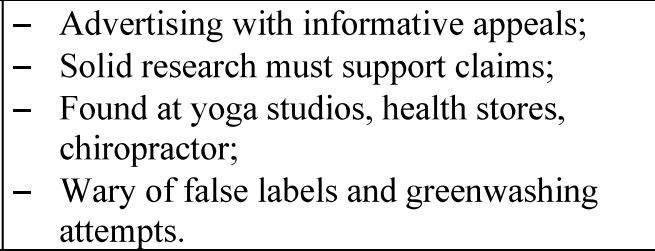 \\
\hline $\begin{array}{l}\text { Keeping up } \\
\text { with the } \\
\text { Joneses }\end{array}$ & $\begin{array}{l}\text { - } \text { Believe that a sustainable lifestyle reflects a } \\
\text { higher social status; } \\
\text { - Influenced by their working and social } \\
\text { environment; } \\
\text { - Want to appear trendy and progressive. }\end{array}$ & $\begin{array}{ll}- & \text { Emotional appeals related to their status; } \\
- & \text { Tend to live in green and upscale } \\
& \text { communities; } \\
\text { - } & \text { Ready to spend more money than other } \\
& \text { groups to appear 'green.' }\end{array}$ \\
\hline Tree-huggers & $\begin{array}{l}\text { - A diet that has the lowest environmental } \\
\text { footprint; } \\
\text { - Concern for the environment and animals } \\
\text { drives consumption decisions; } \\
\text { - Not concerned about health } \\
\text { implications/effectiveness. }\end{array}$ & $\begin{array}{l}\text { - } \\
\text { (concertising with emotional appeals } \\
\text { toward animals); } \\
-\quad \text { Ready to sacrifice product effectiveness; } \\
\text { - } \\
\text { Consume 'vegan junk-food' (no concern } \\
\text { for health). }\end{array}$ \\
\hline $\begin{array}{l}\text { Mom is } \\
\text { always on a } \\
\text { diet }\end{array}$ & $\begin{array}{l}\text { - Weight goals of the dietary gatekeeper } \\
\text { shape the decisions relating to food } \\
\text { consumption; } \\
\text { - Not concerned about health or } \\
\text { environmental implications. }\end{array}$ & $\begin{array}{l}\text { - Emotional appeals stimulating positive } \\
\text { emotions; } \\
\text { - } \\
\text { - } \\
\text { The most susceptible to miracle claims; } \\
\text { health claims. }\end{array}$ \\
\hline
\end{tabular}

\section{FUTURE RESEARCH DIRECTIONS}

This research opens a discussion on the role of the family in socialization towards sustainable food consumption. We have highlighted the importance of self-endorsement and autonomy for the long-lasting effect of this socialization. The concept of autonomy is perceived differently across cultures (Iyengar \& DeVoe, 2003; Markus \& Kitayama, 2003), with important differences seen between collectivistic and individualistic cultures. In the former, young adults might pay more attention to societal norms and thus refer back to their parents' consumption patterns even when they live autonomously (Chen, et al., 2013). Therefore, future research should compare long-lasting family socialization towards sustainable food consumption in individualistic and collectivistic cultures. Moreover, food consumption and food culture are related to geographical location (Geeraert, 2013), which may have implications for sustainable consumption. Future studies could compare the collective consumption of specific product categories in different countries or geographical regions.

This research focused on the content of the communication, namely what kind of values are communicated in the process of socializing towards sustainable food consumption. Therefore, future studies should consider other family-related factors that influence young adults to change their consumption patterns. As the previous research showed that the internalization of behaviors is fostered by autonomy support, clarity of expectations, personal involvement (Grusec \& Davidov, 2007), and the household's emotional climate (Moore, Wilkie, \& Dersochers, 2017), as well as, family structure e.g. single parent, or two separate households (Moore, Wilkie, \& Desrochers, 2017), these factors should be taken into account in future research. Other factors may include, but are not limited to, economic reasons (Hamilton, 2009; Curtis, 2000), or dietary preferences of romantic partners (Hasford, Kidwell, \& LopezKidwell, 2018). 


\section{REFERENCES:}

Arnett, J. J. (2000). Emerging adulthood: A theory of development from the late teens through the twenties. American Pyschologist, 55(5), 469-480.

Bandura, A. (1977). Social learning theory. Englewood Cliffs, NJ: Prentice Hall.

Baumrind, D. (1980). New directions in socialization research. American Psychologist, 35(7), 639-652.

Belch, M. A., \& Willis, L. A. (2002). Family decision at the turn of the century: Has the changing structure of households impacted the family decision-making process? Journal of Consumer Behaviour, 2(2), 111-124.

Bennett, G. \& Freya W. (2011). Mainstream Green: Moving Sustainability From Niche to Normal. Retrieved from http://assets.ogilvy.com/truffles_email/ogilvyearth/Mainstream_Green.pdf.

Bradford, T. W., \& Sherry Jr, J. F. (2015). Domesticating Public Space through Consumption Ritual: Tailgating as Vestaval. Journal of Consumer Research, 42(1), 130-151.

Brim, O. G. (1966). Socialization through the life cycle. In O. G. Brim and S. Wheeler (Eds.), Socialization After Childhood. (pp. 3-29). New York: John Wiley \& Sons, Inc.

Brough, A. R., Wilkie, J. E., Ma, J., Isaac, M. S., \& Gal, D. (2016). Is Eco-Friendly Unmanly? The Green-Feminine Stereotype and Its Effect on Sustainable Consumption. Journal of Consumer Research, 43(4), 567-582.

Brown, B. B., \& Huang, B. H. (1995). Examining parenting practices in different peer context: Implications for adolescent trajectories. In L. J. Crockett \& A. C. Crouter (Eds.), Pathways through adolescence: Individual development in relation to social contexts (pp. 151-174). Hillsdale, NJ: Lawrence Erlbaum Associates, Inc.

Burns, D. J. (1992). Husband-wife innovative consumer decision making: exploring the effect of family power. Psychology \& Marketing, 9(3). 175-189.

Carlson, L., \& Grossbart, S. (1988). Parental Style and Consumer Socialization of Children. Journal of Consumer Research, 15(1), 77-94.

Carlson, L., Grossbart, S., \& Stuenkel, J.K. (1992). The role of Parental Socialization Types On Differential Family Communication Patterns Regarding Consumption. Journal of Consumer Psychology. 1(1), 31-52.

Chen, B., Vansteenkiste, M., Beyers, W., Soenens, B., \& Van Petegem, S. (2013). Autonomy In Family Decision Making for Chinese Adolescents: Disentangling the Dual Meaning of Autonomy. Journal of Cross-Cultural Psychology, 44(7), 1184-1209.

Chung, C., \& Myers S. L. (1999). Do the Poor Pay More for Food? An analysis of Grocery Store Availability and Food Price Disparities. The Journal of Consumer Affairs, 33(2), 276-296.

Cialdini, R. B. \& Trost, M. R. (1998). Social Influence: Social Norms, Conformity, and Compliance. In D T. Gilbert, S. T. Fiske, and G. Lindzey (Eds.), The Handbook of Social Psychology (pp.151-192). New York, NY: McGraw-Hill.

Clulow, C. (1993). New Families? Changes in Societies and Family Relationships. Sexual and Marital Therapy, 8(3), 269-273.

Collins, R. (2004). Interaction Ritual Chains. Princeton, NJ: Princeton University Press.

Connell, P. M., Brucks, M., \& Nielsen, J. H. (2014). How Childhood Advertising Exposure Can Create Biased Product Evaluations That Persist Into Adulthood. Journal of Consumer Research, 41(1), 119-134.

Cornish, L. S., \& Moraes, C. (2015). The Impact of Consumer Confusion on Nutrition Literacy and Subsequent Dietary Behavior. Psychology \& Marketing, 32(5), 558-574.

Cotte, J., \& Wood S. L. (2004). Families and Innovative Consumer Behavior: A Triadic Analysis of Sibling and Parental Influence. Journal of Consumer Research, 31(1), 78-86.

Curtis, J. (2000). Low income, low priority. Marketing, 36-37.

Dahl, D. (2013). Social Influence and Consumer Behavior. Journal of Consumer Research, 40(2), iii-v.

De Gregorio, F. \& Sung, Y. (2010). Understanding Attitudes Toward and Behaviors in Response to Product Placement: A Consumer Socialization Framework. Journal of Advertising, 29(1), 83-96. 
De Groot, J., \& Steg, L. (2007). General beliefs and the theory of planned behavior: The role of environmental concerns in the TPB. Journal of Applied Social Psychology, 37(8), 1817-1836.

Deci, E. L., \& Ryan, R. M. (2002). Self-determination reasearch: Reflections and future directions. In E.

L. Deci \& R. M. Ryan (Eds.), Handbook of self-determination research (pp. 431-441). Rochester, NY: The University of Rochester Press.

Deci, E., \& Ryan, R. M. (1985). Intrinsic motivation and self-determination in human behavior. New York: Plenum Publishing Co.

Denzin, N. K., \& Lincoln, Y. S. (2005). The Sage handbook of qualitative research. UK: Sage.

Ekström K. M. (2007). Parental consumer learning or keeping up with the children. Journal of Consumer Behaviour, 6(4). 203-217.

Ekström, K. M. (2006). Consumer Socialization Revisited. Research in Consumer Behavior, 10(1), 7198.

Epp, A. M., \& Price, L. L. (2008). Family Identity: A Framework of Identity Interplay in Consumption Practices. Journal of Consumer Research, 35(1), 50-70.

FAO (Food and Agriculture Organisation of the United Nations) (2006) Livestock's long shadow. Environmental issues and options. Rome, Italy.

Fila, S. A., \& Smith, C. (2006). Applying the theory of planned behavior to healthy eating behaviors in urban Native American youth. International Journal of Behavioural Nutrition and Physical Activity, 3(1), 11-22.

Fluori, E. (1999). An integration model of consumer materialism: Can economic socialization and maternal values predict materialistic attitudes in adolescent? Journal of Socio-Economics, 28(6), 707-725.

Flurry, L.A. \& Veeck, A. (2009). Children's relative influence in family decision making in Urban China. Journal of Macromarketing, 29(2), 145-159.

Fontana A., \& Frey J. (1994). Interviewing: The Art of Science. In N. Denzin, \& Y, Lincoln (Eds.), Handbook of Qualitative Research (pp.361-376). Thousand Oaks, CA: Sage.

Foxman, E. R., Tansuhai, P. S., \& Ekstrom, K. M. (1989). Family Members' Perceptions of Adolescents' Influence in Family Decision Making. Journal of Consumer Research, 15(4), 482-491.

Geeraert, F. (2013). Sustainability and dietary change: the implications of Swedish food consumption patterns 1960-2006. International Journal of Consumer Studies, 37(2), 121-129.

Gentina, E., Palan, K. M., \& Fosse-Gomez, M. -H. (2012). The practice of using makeup: A consumption ritual of adolescent girls. Journal of Consumer Behaviour, 11(2), 115-123.

Goldstein, N. J., Cialdini, R. B., Griskevicius, V. (2008). A Room with a Viewpoint: Using Social Norms to Motivate Environmental Conservation in Hotels. Journal of Consumer Research, 35(3), 472482.

Goossens, L. (2006). The many faces of adolescent autonomy: Parent-adolescent conflict, behavioral decision-making, and emotional distancing. In S. Jackson \& L. Goossens (Eds.), Handbook of adolescent development. (pp. 135-153). New York, NY: Psychology Press.

Green Industry Analysis. (2017). Green Industry Analysis 2017 - Cost \& Trends. Retrieved from https://www.franchisehelp.com/industry-reports/green-industry-report/

Griskevicius, V., Tybur, J. M., \& Van den Bergh, B. (2010). Going Green to Be Seen: Status, Reputation, and Conspicuous Conservation. Journal of Personality \& Social Psychology, 98(3), 392-404.

Grolnick, W. S., Deci,E. L., \& Ryan, R. M. (1997). Internalization within the Family: The SelfDetermination Theory Perspective. In Joan E. Grusec and Leon Kuczynski (Eds.), Parenting and Children's Internalization of Values-A Handbook of Contemporary Theory (pp.135-161). New York: John Wiley \& Sons.

Grusec, J. E., \& Davidov, M. (2007). Socialization in the Family-The Roles of Parents. In J. E. Grusec and Paul D. Hastings (Eds.), Handbook of Socialization Theory and Research (pp.284-308). New York: Guilford Press.

Hamilton, K. (2009). Consumer decision making in low-income families: The case of conflict avoidance. Journal of Consumer Behaviour, 8(5), 252-267. 
Harper, S. J. A., Dewar, P. \& Diack, B. (2003). The purchase of children's clothing - who has the upper hand? Journal of Fashion Marketing and Management, 7(2), 196-206.

Harris, F., Gordon, R., MacKintosh, A. M., \& Hastings, G. (2015). Consumer Socialization and the Role of Branding in Hazardous Adolescent Drinking. Pyschology \& Marketing, 32(12), 1175-1190

Hasford, J., Kidwell, B., \& Lopez-Kidwell, V. (2018). Happy Wife, Happy Life: Food Choices in Romantic Relationships. Journal of Consumer Research, 44(6), 1238-1256.

Hertwich, E. (2010). Assessing the environmental impacts of consumption and production: priority products and materials. International Panel for Sustainable Resource Management, Working Group on the Environmental Impacts of Products and Materials: Prioritization and Improvement Options. Retrieved from https://doi.org/http://www.unep.org/civilsociety/Portals/59/Documents/SCP-

Holdert, F., Antonides, G. (1997). Family type effects on household members' decision making. Advances in Consumer Research, 24(1), 48-54.

Inglis, V., Ball, K., \& Crawford, D. (2005). Why do women of low socioeconomic status have poorer dietary behaviors than women of higher socioeconomic status? A qualitative exploration. Appetite, 45(3), 334-343.

Iyengar, S. S., \& DeVoe, S. E. (2003). Rethinking the value of choice: Considering cultural mediators of intrinsic motivation. In V. Murphy-Berman \& J. J. Berman (Eds.), Cross-cultural differences in perspectives on the self (pp. 146-191). Lincoln, NE: University of Nebraska Press.

John, D. R. (1999). Consumer socialization of children: A retrospective look at twenty-five years of research. Journal of Consumer Research, 26(3), 183-213.

Kim, Y., \& Choi, M. S. (2005). Antecedents of Green Purchase Behavior: An examination of collectivism, environmental concern and PCE. Advances in Consumer Research, 32(1), 592-599.

Kirk, S. F., Penney, T. L., \& McHugh, T. L. (2010). Characterizing the obesogenic environment: The state of the evidence with directions for future research. Obesity Reviews, 11(2), 109-117.

Kohler, C. F., Rohm, A. J., de Ruter, K., \& Wetzels, M. (2011). Return on Interactivity: The Impact of Online Agents on Newcomer Adjustment. Journal of Marketing, 75(2), 93-108.

Kumar, P. (2016). State of green marketing research over 25 years (1990-2014). Marketing Intelligence \& Planning, 34(1), 137-158.

Kvale, S., \& Brikmann, S. (2009). Interviews: Learning the craft of qualitative research interviewing. Los Angeles: Sage Publications

Lackman, C. \& Lanasa, M. (1993) Family decision-making theory: an overview and assessment. Psychology \& Marketing, 10(2), 81-93.

Leonidou, C. N., \& Leonidou, L. C. (2011). Research into environmental marketing/management: a bibliographic analysis. European Journal of Marketing, 45(1/2), 68-103.

Leonidou, L. C., Leonidou, C. N., Hadjimarcou, J. S., \& Lytovchenko, I. (2014). Assessing the greenness of environmental advertising claims made by multinational industrial firms. Industrial Marketing Management, 43(4), 671-684.

Leonidou, L. C., Leonidou, C. N., Palihawadana, D., \& Hultman, M. (2011). Evaluating the green advertising practices of international firms: a trend analysis. International Marketing Review, 28(1), 6-33.

Lin, P.-C., \& Huang, Y.-H. (2012). The influence factors on choice behavior regarding green products based on the theory of consumption values. Journal of Cleaner Production, 22(1), 11-18.

Lin, Y.-C., \& Chang C.-C. A. (2012). Double Standard: The Role of Environmental Consciousness in Green Product Usage. Journal of Marketing, 76(5), 125-134.

Luchs, M. G., Naylor, R. W., Irwin, J. R.., \& Raghunathan, R. (2010). The sustainability liability: Potential negative effects of ethicality on Product Preference. Journal of Marketing, 74(5), 18-31.

Maccoby, E. E. (2007). Historical Overview of Socialization Research and Theory. In J. E. Grusec and P. D. Hastings (Eds.), Handbook of Socialization: Theory and Research (pp.13-41). New York, NY: Guilford Press. 
Markus, H. R., \& Kitayama, S. (2003). Models of agency: Sociocultural diversity in the construction of action. In V. Murphy-Berman, \& J. J. Berman (Eds.), Cross-cultural differences in perspectives on self (pp. 1-57). Lincoln: University of Nebraska Press.

McGinnis, J. M., Gootman, J. A., \& Kraak, V. I. (2006). Food Marketing to Children and Youth: Threat or Opportunity? Washington, DC: National Academies Press.

McLeod, J. M., \& O'Keefe, G. J. (1972). The Socialization Perspective and Communication Behavior. In F. G. Kline \& P. J. Tichenor (Eds.), Current Perspectives in Mass Communication Research (pp. 121-168). Beverly Hills, CA: Sage Publications.

McNeal, J. (1987). Children As Consumers: Insights and Implications. Lexington, MA: Lexington Books

McNeal, J. U. (2007). On becoming a consumer. Oxford, UK: Butterworth-Heinemann.

Michealidou, N., Christodoulides, G., \& Torova, K. (2012). Determinants of healthy eating: a crossnational study on motives and barriers. International Journal of Consumer Studies, 36(1), 17-22.

Mihalic, W. \& Elliott, D. (2005). A social learning theory, model of marital violence. In T. Chibucos \& R. Leite (Eds.), Readings in Family Theory (pp. 98-117). Thousand Oaks, CA: Sage Publications, Inc.

Moisander, J., and Valtonen, A. (2006). Qualitative marketing research: a cultural approach. London, Thousand Oaks \& New Delhi: Sage.

Moisander, J., Valtonen, A., \& Hirsto, H. (2009). Personal interviews in cultural consumer research- Poststructuralist challenges. Consumption, Markets and Culture, 12(4), 329-348.

Moore, E. S., Wilkie, W. L., \& Desrochers, D. M. (2017). All in the Family? Parental Roles in the Epidemic of Childhood Obesity. Journal of Consumer Research, 43(5), 824-859.

Moore, E. S., Wilkie, W. L., \& Lutz, R. J. (2002). Passing the Torch: Intergenerational Influences as a Source of Brand Equity. Journal of Marketing, 66(2), 17-37.

Moore, R. L., \& Moschis, G. P. (1981). The role of family communication in consumer learning. Journal of Communication, 31(3), 42-51.

Moschis, G. P. (1985). The Role of Family Communication in Consumer Socialization of Children and Adolescents. Journal of Consumer Research, 11(4), 898-913.

Moschis, G. P., \& Churchill Jr., G. A. (1978). Consumer Socialization: A Theoretical and Empirical Analysis. Journal of Marketing Research, 15(4), 599-609.

O'Malley, L., \& Prothero A. (2007). Contemporary families and consumption. Journal of Consumer Behaviour, 6(4), 159-163.

Palan, K. M., \& Wilkes, R. E. (1997). Adolescent-parent interaction in family decision making. Journal of Consumer Research, 24(2), 159-169.

Peattie, K. (2010). Green Consumption: Behavior and Norms. Annual Review of Environment and Resources, 35(1), 195-228.

Phinney, J. S. (1989). Stages of ethnic identity development in minority group adolescents. Journal of Early Adolescence, 9(1/2), 34-49.

Qu, S. Q., \& Dumay, J. (2011). The qualitative research interview. Qualitative Research in Accounting and Management, 8(3), 238-264.

Raven, B. H. (1992). A Power/Interaction Model of Interpersonal Influence: French and Raven Thirty Years Later. Journal of Social Behavior \& Personality, 7(2), 217-244.

Reid, M., Worsley, A., \& Mayondo, F. (2015). The Obesogenic Household: Factors Influencing Dietary Gatekeeper Satisfaction with Family Diet. Psychology \& Marketing, 32(5), 544-557.

Reisch, L.A. \& Gwozdz, W. (2011). Chubby cheeks and climate change: childhood obesity as a sustainable development issue. International Journal of Consumer Studies, 35(1), 3-9.

Richey, R. G. Jr., Musgrove, C. F., Gillison, S. T., \& Gabler, C. B. (2014). The effects of environmental focus and program timing on green marketing performance and the moderating role of resource commitment. Industrial Marketing Management, 43(7), 1246-1257.

Richins, M. L., \& Chaplin, L. N. (2015). Material Parenting: How the Use of Goods in Parenting Fosters Materialism in the Next Generation. Journal of Consumer Research, 41(6), 1333-1357. 
Riet, J. V., Sijtsema, S. J., Dagevos, H., \& De Bruijn, G. J. (2011). The Importance of Habits in Eating Behaviour. An Overview and Recommendations for Future Research. Appetite, 57(3), 585-596.

Riley, R. W. (1996). Revealing socially constructed knowledge through quasi-structured interviews and grounded theory analysis. Journal of Travel \& Tourism Marketing, 5(1-2), 21-40.

Rolland, D., \& Bazzoni, J. O. (2009). Greening corporate identity: CSR online corporate identity reporting. Corporate Communications: An International Journal, 14(3), 249-263.

Ronka, A. \& Pirjo, K. (2009). Everyday Family Life: Dimensions, Approaches, and Current Challenges. Journal of Family Theory \& Review, 1(2), 87-102.

Rook, D. W. (1985). The ritual dimension of consumer behavior. Journal of Consumer Research, 12(3), 251-265.

Rose, G. M. (1999). Consumer Socialization, Parental Style and Development Timetables in the United States and Japan. Journal of Marketing, 63(3), 105-119.

Rosenstock, I. M., Strecher, V. J., \& Becker, M. H. (1994). The health belief model and HIV risk behavior change. In R. J. DiClemente \& J.L Peterson (Eds.), Preventing AIDS: Theories and methods of behavior interventions (pp. 5-24). Springer, New York: Plenum

Ryan, R. M., \& Deci, E. L. (2000). Self-determination theory and the facilitation of intrinsic motivation, social development, and well-being. American Psychologist, 55(1), 68-78.

Ryan, R. M., \& Deci, E. L. (2011). A self-determination theory perspective on social, institutional, cultural, and economic supports for autonomy and their importance for well-being. In V. I. Chirkov, R. M. Ryan, \& K. M. Sheldon (Eds.), Cross-cultural advancements in positive psychology: Human autonomy in cross-cultural context (pp. 45-64). New York: Springer.

Schau, H. J., Mun iz, A. M., \& Arnould, E. J. (2009). How Brand Community Practices Create Value. Journal of Marketing, 73(5), 30-51.

Schwartz, B. (2000). Self-determination: The tyranny of freedom. American Psychologist, 55(1), 79-88.

Sheldon, K. M., \& Elliot, A. J. (1999). Goal striving, need satisfaction, and longitudinal well-being: The Self-Concordance Model. Journal of Personality and Social Psychology, 76(3), 546-557.

Sheth, N. \& Mittal, B. (2004) Customer Behaviour: A Managerial Perspective. Mason, OH: Thomson South-Western.

Sinkovics, R. R., Penz, E., \& Ghauri, P. N. (2008). Enchancing the Trustworthiness of Qualitative Research in International Business. Management International Review, 48(6), 689-713.

Smith, A. L., Ntoumanis, N., Duda, J. L., \& Vansteenkiste, M. (2011). Goal striving, coping, and wellbeing: A prospective investigation of the self-concordance model in sport. Journal of Sports \& Exercise Psychology, 33(1), 124-145.

Steinfield, H., Gerber, P., Wassenaar, T. D., Castel, V., Rosales, M., Rosales, M., \& de Haan, C. (2006). Livestock's Long Shadow: Environmental Issues and Options. Retrieved from http://www.fao.org/docrep/010/a0701e/a0701e00.HTM

Stern, B. B., Thompson, C. J., \& Arnould, E. J. (1998). Narrative analysis of a marketing relationship: The consumer's perspective. Psychology \& Marketing, 15(3), 195-214.

Steyvers, M., \& Tenenbaum, J. B. (2005). The Large-Scale Structure of Semantic Networks: Statistical Analyses and a Model of Semantic Growth. Cognitive Science, 29(1), 41-78.

Su, C., Fern, E. F., \& Ye, K. (2003). A Temporal Dynamic Model of Spousal Family Purchase Decision Behavior. Journal of Marketing Research, 40(3), 268-281.

Swinburn, B., Caterson, I., Seidell, J., \& James, W. (2004). Diet, nutrition and the prevention of excess weight gain and obesity. Public Health Nutrition, 7(1), 123-146.

Tanner, C., \& Kast 2.W. (2003). Promoting Sustainable Consumption: Determinants of Green Purchases by Swiss Consumers. Psychology \& Marketing, 20(10), 883-902.

Thomas, T. C., Price, L. L., \& Schau, H. J. (2013). When Differences Unite: Resource Dependence in Heterogeneous Consumption Communities. Journal of Consumer Research, 39(5), 1010-1033.

Turner, H., \& West, R. (2006). Perspectives on family Communication. Mayfield Publishing Company, London. 
UNEP (United Nations Environment Programme) (2010). Assessing the environmental impacts of consumption and production: priority products and materials. A Report of the Working Group on the Environmental Impacts of Products and Materials to the International Panel for Sustainable Resource Management.

Wallendorf, M., \& Arnould, E. J. (1991). We Gather Together: Consumption Rituals of Thanksgiving Day. Journal of Consumer Research, 18(1), 13-31.

Wang, E. W., Lambert, M. C., Johnson, L. E., Boudreau, B., Breidenbach, R., \& Baumann, D. (2012) Expediting permanent placement from foster care systems: The role of family decision making. Children and Youth Services Review, 34(4), 845-850.

Wang, P., Liu, Q., \& Qi, Y. (2014). Factors influencing sustainable consumption behaviors: a survey of the rural residents in China. Journal of Cleaner Production, 63, 152-165.

Wang, Y., Beydoun, M. A., Li, J., Liu, Y., \& Moreno, L. A. (2011). Do Children and Their Parents Eat a Similar Diet? Resemblance in Child and Parental Dietary Intake: Systematic Review and MetaAnalysis. Journal of Epidemiology and Community Health, 65(2), 177-89.

Wansink, B., \& Sobal, J. (2007). Mindless Eating: The 200 daily food decisions we overlook. Environment and Behavior, 39(1), 106-123.

Ward, S. (1974). Consumer socialization. Journal of Consumer Research, 1(2), 1-14.

Ward, S. (1980). Consumer socialization. In H. H. Kassarjian \& T. S. Robertson (Eds.), Perspectives consumer behavior (pp.380-396). Glenville, IL: Scott Foresman

Webster C. (1994). Effects of Hispanic ethnic identification on marital roles in the purchase decision process. Journal of Consumer Research, 21(2), 319-331.

Weinberger, M. F. (2015). Dominant Consumption Rituals and Intragroup Boundary Work: How NonCelebrants Manage Conflicting Relational and Identity Goals. Journal of Consumer Research, 42(3), 378-400.

Wut, T. M., \& Chou. T. (2013). Do family members agree on family purchase decision? - an empirical study among families in Hong Kong. International Journal of Consumer Studies, 37(3), 344-350.

Xu, J., Shim, S., \& Almeida, D. (2004). Ethic Identity, Socialization Factors and Culture-Specific Consumption Behavior. Psychology \& Marketing, 21(2), 93-112. 